\title{
Probing the nanofriction of non-halogenated phosphonium- based ionic liquid additives in glycol ether oil on titanium surface
}

\author{
Xiuhua QIU ${ }^{1}$, Linghong LU ${ }^{2}$, Zhenyu QU ${ }^{1}$, Jiongtao LIAO ${ }^{1}$, Qi FAN ${ }^{1}$, Faiz Ullah SHAH ${ }^{3}$, Wenling ZHANG ${ }^{4}$, \\ Rong $\mathbf{A N}^{1, *}$ \\ ${ }^{1}$ Herbert Gleiter Institute of Nanoscience, Department of Materials Science and Engineering, Nanjing University of Science and Technology, \\ Nanjing 210094, China \\ ${ }^{2}$ State Key Laboratory of Materials-Oriented Chemical Engineering, College of Chemical Engineering, Nanjing Tech University, Nanjing \\ 211816, China \\ ${ }^{3}$ Chemistry of Interfaces, Luleå University of Technology, Luleå 97187, Sweden \\ ${ }^{4}$ Department of Mechanical Engineering, Nanjing University of Science and Technology, Nanjing 210094, China \\ Received: 10 August 2020 / Revised: 29 October 2020 / Accepted: 07 January 2021 \\ (C) The author(s) 2021.
}

\begin{abstract}
The nanofrictional behavior of non-halogentated phosphonium-based ionic liquids (ILs) mixed with diethylene glycol dibutyl ether in the molar ratios of 1:10 and 1:70 was investigated on the titanium (Ti) substrate using atomic force microscopy (AFM). A significant reduction is observed in the friction coefficient $\mu$ for the IL-oil mixtures with a higher IL concentration (1:10, $\mu \sim 0.05)$, compared to that for the lower concentration 1:70 $(\mu \sim 0.1)$. AFM approaching force-distance curves and number density profiles for IL-oil mixtures with a higher concentration revealed that the IL preferred to accumulate at the surface forming IL-rich layered structures. The ordered IL-rich layers formed on the titanium surface facilitated the reduction of the nanoscale friction by preventing direct surface-to-surface contact. However, the ordered IL layers disappeared in the case of lower concentration, resulting in an incomplete boundary layers, because the ions were displaced by molecules of the oil during sliding and revealed to be less efficient in friction reduction.
\end{abstract}

Keywords: ionic liquid; nanofriction; atomic force microscopy (AFM); ordering; density

\section{Introduction}

Friction is one of the major causes that results in energy and material losses in many technical applications, including nano-fluidic technology, micro/nano electromechanical systems, etc. Implementing lubrication technologies, such as solid or liquid lubricants, enable the decrease of friction and wear between the sliding contacts, thus potentially reducing the energy losses by $18 \%-40 \%$ [1]. The low friction in the elastohydrodynamic regime, high thermal conductance, as well as the long-term endurance, enable the liquid lubricants more advantageous than solid lubricants [2]. While conventional liquid lubricants have insurmountable shortcomings [3], e.g., volatility, degradability, and narrow liquid range. Such oil lubricants adhere weakly to solid surfaces, and can be easily squeezed out of the contacts during sliding, resulting in direct surface-to-surface contacts, thus providing a high friction [4].

Ionic liquids (ILs) consisting of cations and anions, are liquid-state salts at room temperature, possessing high thermal stability, non-flammability and ionic conductivity, molecular designability, non-volatility, and so on [5-8]. Typically, ILs offer an ability to resist 'squeeze out' because of their strong interactions with solid surfaces, including van der Waals and electrostatic forces, as well as hydrogen-bonding interactions

* Corresponding author: Rong AN, E-mail: ran@njust.edu.cn 
[5, 9-14]. The main limitation of ILs is their relatively higher price compared to conventional lubricants. However, this problem can be tackled by mixing ILs with conventional lubricating base oils to reduce the cost and improve their lubrication performance together with physicochemical properties $[15,16]$.

It has been found that the lubricant employing ILs as additives in base oils boosts the lubricating efficiency and reduces the cost to increase their potential applicability at industrial scales [4, 8, 17-20]. A phosphonium-based IL adding into the hydrocarbon oil with an IL concentration of $5 \mathrm{wt} \%$, has demonstrated a significant reduction in the friction coefficient in steel-cast iron contacts [21]. It is observed that at the nanoscale, only $2.0 \mathrm{~mol} \%$ of an IL in hexadecane lubricates silica by forming robust boundary layers and the friction forces are significantly reduced than the neat hexadecane [15]. In another study, it was found that the friction is reduced effectively with the addition of $1 \mathrm{wt} \%$ of quaternary ammonium IL to poly- $\alpha$-olefin oil, while a further increase of the IL from $1 \mathrm{wt} \%$ to $3 \mathrm{wt} \%$ did not make any significant change in the friction-reducing characteristic [14].

Obviously, the tribological performance may not be necessarily improved by a higher concentration of ILs [8]. For example, $8 \mathrm{wt} \%$ imidazolium-based ILs in glycerol showed a higher friction coefficient at steel-steel contacts than that of $0.63 \mathrm{wt} \%$ [22]. While in the rapeseed oil lubrication, the friction coefficient and wear volume increased as the IL concentration increased from $1 \mathrm{wt} \%$ to $3 \mathrm{wt} \%$ [23]. Our recent work even demonstrated a 'negative' load-dependent nanofriction in IL-glycol ether mixtures with an IL concentration of $75 \mathrm{wt} \%$ on the titanium surface, i.e., the friction decreases with increasing load, not following the Amontons' law [24].

Furthermore, lubricant formulations can be specific to different tribological material systems. A lubricant might be able to improve tribological performance in one system, while the same lubricant may not be as effective in protecting other materials against the friction and wear [25]. Therefore, it led to an immediate controversy over the mixed IL-oil lubricants on the improvement of the tribological performance, which is necessary to be clarified. And there is an urge to understand the underlying mechanisms of ILs-based lubricants in various tribological materials and to improve the lubrication performance of non-ferrous materials, which remains a challenge for the scientific community.

As is known, the halogenated ILs exhibit excellent lubricity [26-28], mainly with fluorine as the halogen element for the anion, e.g., tetrafluoroborate and hexafluorophosphate. When the halogenated ILs are used for lubrication, the formed metal fluorides on the sliding surfaces act as the boundary lubricating layer [26, 29]. However, the most studied halogen containing ILs as oil additives may release toxic and corrosive products including hydrofluoric acid (HF) into the surrounding environment, causing corrosion and toxicity to the contacts [30]. This can be avoided via a proper molecular design of ILs, e.g., the employment of halogen-free ILs in lubrication [31]. Thus, in this work, a series of halogen-free phosphoniumbased ILs are studied as IL additives into diethylene glycol dibutyl ether base oil, with molar ratios of 1:10 and 1:70.

A systematic nano-frictional behavior of the IL-oil mixtures were investigated on the titanium (Ti) substrate. Ti was employed herein as the substrate to be lubricated, because Ti has wide applications, e.g., spacecraft triboelement [32], due to its high melting point and strength-to-weight ratio, as well as excellent corrosion resistance [33-36]. However, the Ti surface is one of the most difficult metal to lubricate and usually lead to high friction and wear, limiting its application in mechanical systems [35, 37, 38]. This study is an attempt to unveil the underlying mechanisms of ILs-based lubricants in Ti contacts.

\section{Experiments and simulations}

\subsection{Materials}

The base oil, i.e., diethylene glycol dibutyl ether (DEGDBE, purity > 99\%) used in this study was purchased from ACROS organics. Titanium (Ti, foil, thickness $0.25 \mathrm{~mm}, \alpha$-Ti phase) substrates with $99.7 \%$ purity and araldite Resin CY212 (CY212) were obtained from Sigma-Aldrich, and Ti was pre-cleaned in ethanol under ultrasonic conditions for 30 minutes. Trihexyltetradecylphosphonium dicyanamide, $\left[\mathrm{P}_{6,6,6,14}\right][\mathrm{DCA}]$ 
was purchased from Cytec. Both benzyldimenthylamine (BDMA) and dodecenyl succinic anhydride (DDSA) were from Sinopharm Chemical Reagent Co., Ltd. The borosilicate glass microspheres and NSC35 tipless $\mathrm{Cr}-\mathrm{Au}$ coated cantilevers were respectively from SPI Supplies and Mikromasch.

\subsection{Sample preparation}

The ILs including trihexyltetradecylphosphonium bis(salicylato)borate, $\left[\mathrm{P}_{6,6,6,14}\right][\mathrm{BScB}]$; trihexyltetradecylphosphonium bis(oxalato)borate, $\left[\mathrm{P}_{6,6,6,14}\right][\mathrm{BOB}]$; trihexyltetradecylphosphonium bis(mandelato)borate, $\left.\left[\mathrm{P}_{6,6,6,14]}\right] \mathrm{BMB}\right]$; and tributyloctylphosphonium bis (salicylato)borate, $\left[\mathrm{P}_{4,4,4,8}\right][\mathrm{BScB}]$ were synthesized using the previously reported synthetic methods [39]. The chemical structures of $\left[\mathrm{P}_{4,4,4,8}\right]^{+},\left[\mathrm{P}_{6,6,6,14}\right]^{+}$cations, and $[\mathrm{BScB}]^{-},[\mathrm{DCA}]^{-},[\mathrm{BOB}]^{-},[\mathrm{BMB}]^{-}$anions, as well as the base oil DEGDBE are shown in Fig. 1.

The samples were prepared by dissolving these ILs in the DEGDBE oil at varying molar ratios, i.e., 1:10, 1:70. The wetting IL-oil mixtures and neat oil were deposited onto Ti surfaces. As for the case with a higher IL concentration, i.e., the molar ratio of $1: 1$, we had already studied that in our previous work [24].

\subsection{Force measurements}

Friction force measurements were performed as what we did previously [24]. In brief, these forces were measured on a Dimension Icon atomic force microscopy (AFM, Bruker) in contact mode at ambient conditions.
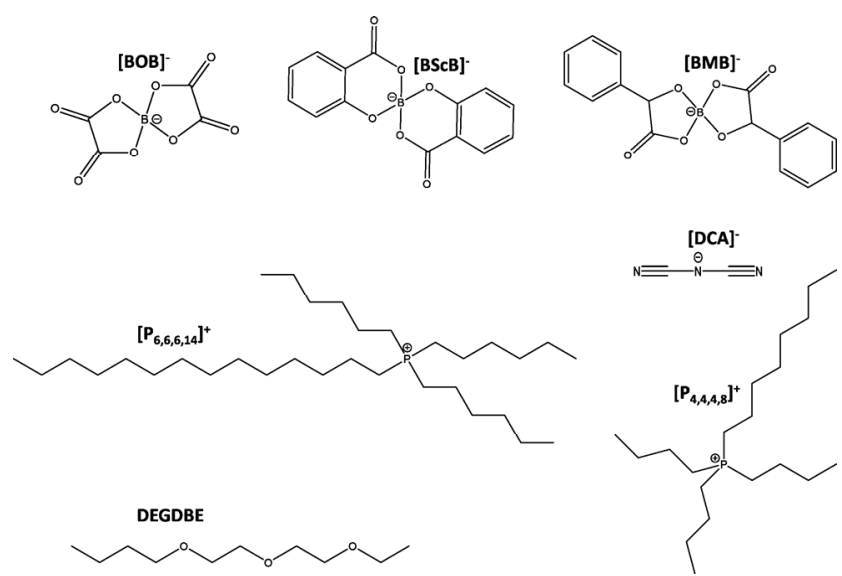

Fig. 1 Structural illustration and abbreviations of $[\mathrm{BOB}]^{-}$, $[\mathrm{BScB}]^{-},[\mathrm{BMB}]^{-},[\mathrm{DCA}]^{-},\left[\mathrm{P}_{4,4,4,8}\right]^{+},\left[\mathrm{P}_{6,6,6,14}\right]^{+}$, as well as the base oil DEGDBE.
$\mathrm{Si}_{3} \mathrm{~N}_{4}$ cantilever tips (DNP-10, a tip with tip radius of $20 \mathrm{~nm}$ ) were employed with a scan rate of $2 \mathrm{~Hz}$ and scan size of $5 \mu \mathrm{m} \times 5 \mu \mathrm{m}$. The tips used in friction measurements were calibrated using the thermal tune method. The lateral force (in V) was transformed into a true friction force (in N) following Liu's method [40]. Detailed experiment processes for friction force measurements were addressed in Electronic Supplementary Material (ESM).

The force-distance curves were captured with AFM glass colloidal probe $(20 \mu \mathrm{m}$ in dimension), which were performed as that in our recent work [41]. The borosilicate glass microspheres were stick to NSC35 tipless $\mathrm{Cr}-\mathrm{Au}$ coated cantilevers (Cantilever A) via epoxy glue (BDMA:DDSA:CY212 = 1:10:10 in volume ratio).

\subsection{Surface characterization}

The surface morphologies of the bare Ti substrate, neat oil coated $\mathrm{Ti}$, and IL-oil mixture coated $\mathrm{Ti}$ were observed by AFM tapping mode. Attenuated total reflection Fourier-transform infrared spectroscopy (ATR-FTIR, Nicolet IS-10, Thermo Fisher Scientific) and X-ray photoelectron energy spectra (XPS, Thermo VG Scientific X-ray photoelectron spectrometer with a monochromatic $\mathrm{Al} \mathrm{K} \alpha \mathrm{X}$-ray) were used to characterize the molecular structural information of the IL-oil mixtures, neat ILs, and oil on Ti.

\subsection{Molecular simulations}

To uncover the fundamental mechanism of Ti surfaces lubricated with IL-oil mixtures at molecular level, molecular dynamics (MD) simulation was performed to investigate the number density distribution of $\left[\mathrm{P}_{6,6,6,14}\right][\mathrm{BScB}]$-oil mixtures with a molar ratio of 1:10. As is known, the Ti surface is usually covered by native dense titanium dioxide layers [42], we thus employed the rutile in MD simulations to mimic the substrate that was used in AFM experiments. The tip is almost a flat surface at the microscale, forming a slit with the substrate surface. Thus, a slit pore model (pore width of $10.7 \mathrm{~nm}$ ) composed of a bilayer graphene tip and rutile (110) substrate (thickness = $0.903 \mathrm{~nm}$ ) was used. Simulation details are described in ESM. 


\section{Results and discussion}

\subsection{Interactions of IL-oil mixtures with the $\mathrm{Ti}$ substrate}

The local surface topographic images of the pristine bare $\mathrm{Ti}$, neat DEGDBE oil on $\mathrm{Ti}$, and IL-oil mixtures on $\mathrm{Ti}$, were characterized using AFM to track the oil or the IL-oil film on the Ti surface in Fig. 2. The pristine bare Ti substrate exhibits an irregular rough morphology with cracks/scratches and particles (Fig. 2(a), left panel). In comparison, the morphology of the Ti surface, upon deposition by drop-casting neat oil (Fig. 2(a), right panel) or IL-oil mixtures (molar ratios of 1:70 and 1:10, Figs. 2(b)-2(f)), showed less cracks/scratches and particles. The unexpected invisible oil or IL-oil film is probably due to the roughness of the Ti substrate which smears the thin film on the surface. The non-directly observed films of neat oil or IL-oil mixtures enabled the reduction of surface roughness, leading to less cracks/scratches and particles.

XPS analysis was performed to get deeper insights into the interactions of IL-oil mixtures with the $\mathrm{Ti}$ substrate. Figure 3 shows high-resolution spectra of O 1s, P 2p, B 1s scans for the $\left[\mathrm{P}_{6,6,6,14}\right][\mathrm{BScB}]$-oil mixtures coated Ti substrate (1:70, 1:10). The $\mathrm{O} 1 \mathrm{~s}$ spectra shows four distinct features: the peak at $530.5 \mathrm{eV}$ is caused by $\mathrm{O}-\mathrm{Ti}$ bonding from the underlying $\mathrm{Ti}$ substrate while the other three peaks at 531.8, 532.4, $533.3 \mathrm{eV}$ are attributed to $\mathrm{C}=\mathrm{O} / \mathrm{O}=\mathrm{C}-\mathrm{O}$ [43], O-B [44, 45], and $\mathrm{O}-\mathrm{C}[46]$ bonds in the $[\mathrm{BScB}]^{-}$anion. In the middle panel of Fig. 3, P 2p1/2 and P 2p3/2 peaks are identified at 130.0 and $131.8 \mathrm{eV}$, respectively [47], and a distinctive peak observed at $132.5 \mathrm{eV}$ is assigned to the $\mathrm{P}-\mathrm{C}$ bond in the $\left[\mathrm{P}_{6,6,6,614}\right]^{+}$cation. The overlap of $B$ 1s and $P$ 2s photopeaks was observed in the right panel of Fig. 3, which "occurs heavily in oxide-based samples containing both boron and phosphorus" [48]. The B 1s core-level spectra exhibit a peak at $189.9 \mathrm{eV}$, due to $\mathrm{B}^{-} \mathrm{O}_{4}$ linkage [49] in the $[\mathrm{BScB}]^{-}$anion, and the $\mathrm{P} 2 \mathrm{~s}$ region is centered at $192.1 \mathrm{eV}$. The $\mathrm{O} 1 \mathrm{~s}, \mathrm{P} 2 \mathrm{p}$, and $B$ 1s spectra in $\left[\mathrm{P}_{6,6,6,14}\right][\mathrm{BScB}]$-oil mixtures $(1: 70$, 1:10) do not show any significant changes in the binding energy values and shapes of the signal. Comparing the XPS spectra data for other systems involving $\left[\mathrm{P}_{6,6,6,14}\right][\mathrm{DCA}]-,\left[\mathrm{P}_{6,6,6,14}\right][\mathrm{BOB}]-,\left[\mathrm{P}_{6,6,6,14}\right][\mathrm{BMB}]-$, and
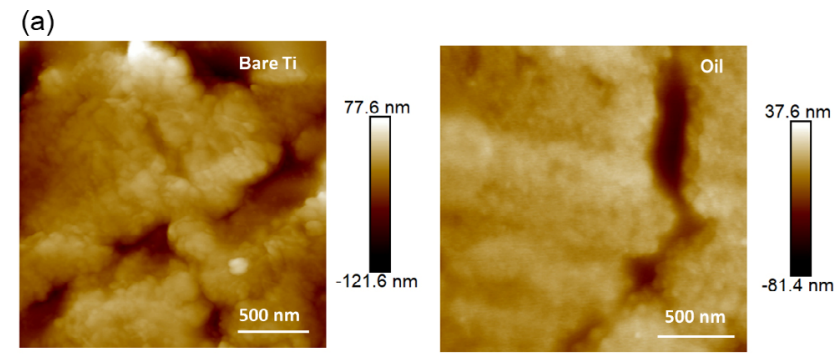

(b)
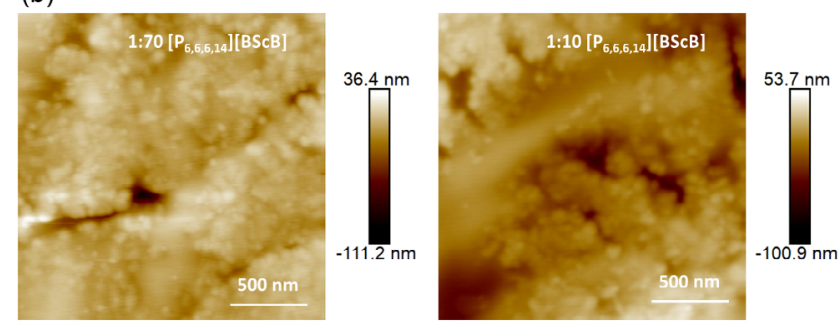

(c)
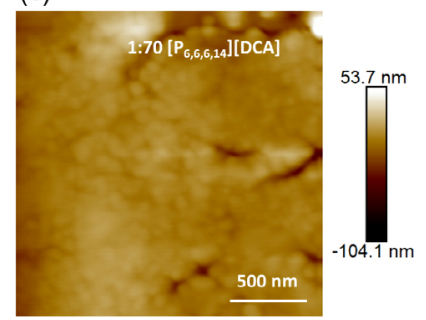

(d)
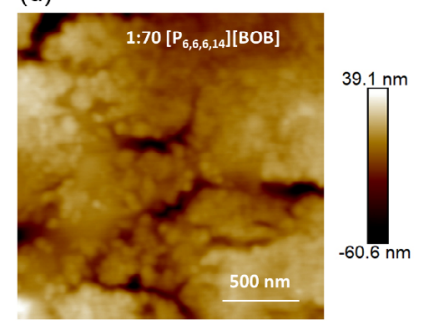

(e)

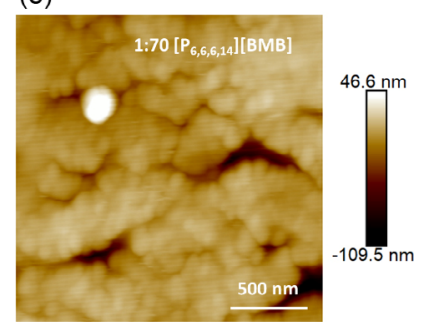

(f)
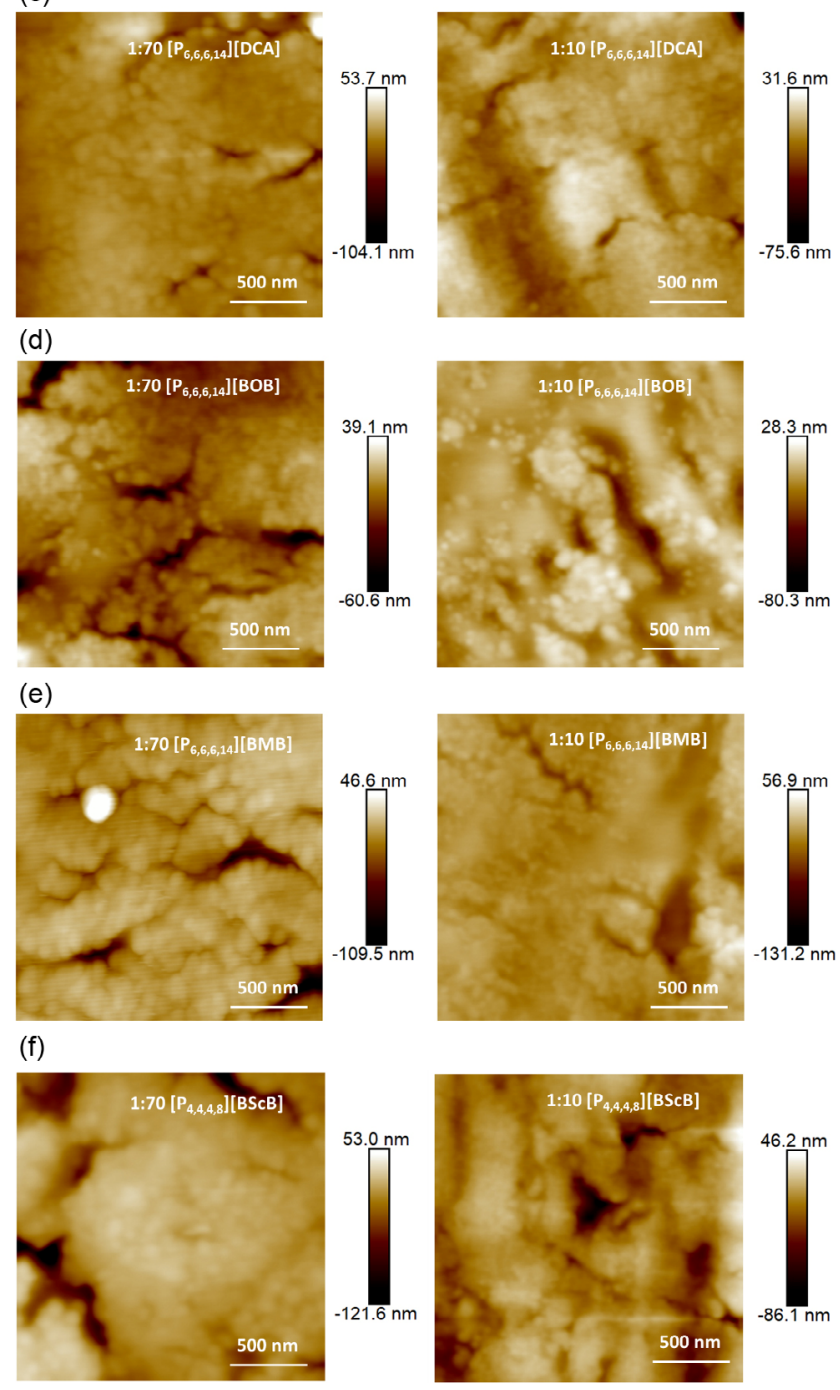

Fig. 2 AFM topographic images for (a) pristine bare Ti substrate and neat DEGDBE oil coated $\mathrm{Ti}$, and (b-f) the IL-oil mixtures coated Ti $(1: 70,1: 10)$. 

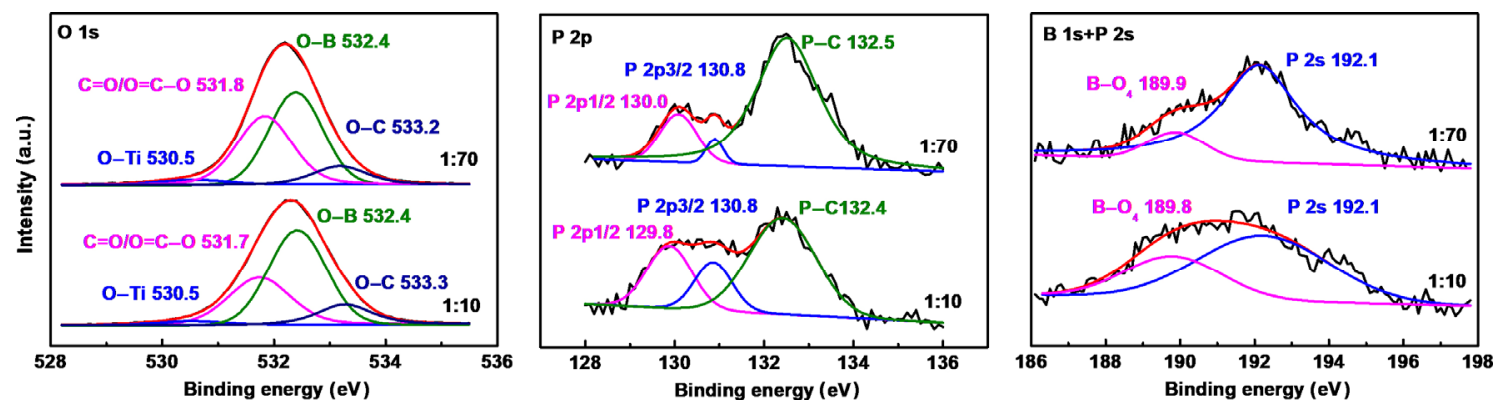

Fig. 3 High-resolution spectra of $\mathrm{O} 1 \mathrm{~s}, \mathrm{P} 2 \mathrm{p}$, and $\mathrm{B} 1 \mathrm{~s}+\mathrm{P} 2 \mathrm{~s}$ scans for $\left[\mathrm{P}_{6,6,6,14}\right][\mathrm{BScB}]$-oil mixtures on Ti (1:70, 1:10).

$\left[\mathrm{P}_{4,4,4,8}\right][\mathrm{BScB}]$-oil mixtures at $\mathrm{Ti}$ surfaces $(1: 70,1: 10$, in Fig. $\mathrm{S} 1$ in the ESM), there are still no changes in the binding energy values and shapes of signals for the characteristic peaks.

FTIR spectra were employed to examine the interactive strength of the oil, neat ILs, and IL-oil mixtures with the underlying Ti substrates. Figure 4 shows FTIR spectra of the bare Ti substrate, neat oil, neat IL, as well as the $\left[\mathrm{P}_{6,6,6,614}\right][\mathrm{BSCB}]$-oil mixture on $\mathrm{Ti}$ surface. A comparison of the FTIR spectra for the other ILs $\left[\mathrm{P}_{6,6,6,14}\right][\mathrm{DCA}],\left[\mathrm{P}_{6,6,6,14}\right][\mathrm{BOB}],\left[\mathrm{P}_{6,6,6,14}\right][\mathrm{BMB}]$, and $\left[\mathrm{P}_{4,4,4,8}\right][\mathrm{BScB}]$ mixed with the oil in different molar ratios on Ti is shown in Fig. S2 in the ESM.

Figures 4 and S2 in the ESM exhibit stretching vibrations in the frequency range from 2,800 to $3,000 \mathrm{~cm}^{-1}$, which are caused by the aliphatic $\mathrm{C}-\mathrm{H}$ groups [50] in the cations of ILs or the oil. The peak at approximately $1,110 \mathrm{~cm}^{-1}$ in the spectrum of the neat DEGDBE oil is attributed to $\mathrm{C}-\mathrm{O}-\mathrm{C}$ bands [51]. The vibrations around $1,685 \mathrm{~cm}^{-1}$ in the neat bulk IL $\left.\left[\mathrm{P}_{6,6,6,14]}\right] \mathrm{BScB}\right]$ are due to $\mathrm{C}=\mathrm{O}$ stretching, while the vibrations around $1,610 \mathrm{~cm}^{-1}$ to the aromatic ring $[50,52]$. The vibrational signatures at 1,604 and $1,270 \mathrm{~cm}^{-1}$ are assigned to $\mathrm{O}-\mathrm{C}=\mathrm{O}$ stretching mode from the [BScB] $^{-}$anion [53]. The band presenting at
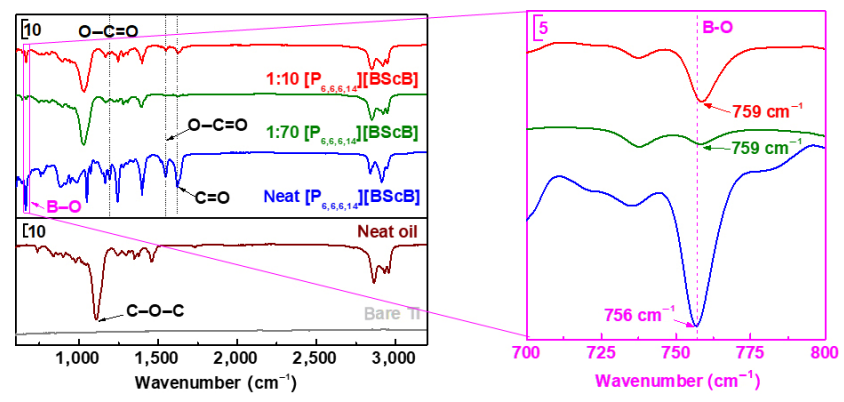

Fig. 4 Comparison of ATR-FTIR spectra for the bare Ti substrate, neat oil, neat IL $\left[\mathrm{P}_{6,6,6,14}\right][\mathrm{BScB}]$, and $\left[\mathrm{P}_{6,6,6,14}\right][\mathrm{BScB}]$-oil mixtures on Ti. around $756 \mathrm{~cm}^{-1}$ in the neat IL is assigned to the $\mathrm{B}-\mathrm{O}$ stretching of the anion $[\mathrm{BScB}]^{-}[52]$.

No significant shift in the characteristic vibrational peaks of the DEGDBE oil is observed in the FTIR spectra when the IL and oil are mixed in the specific concentrations on the Ti surface (1:70, 1:10). While the $\mathrm{B}-\mathrm{O}$ band in $[\mathrm{BScB}]^{-}$anion of the IL was observed to blue shift towards a higher wavenumber at $\sim 759 \mathrm{~cm}^{-1}$ for the IL-oil mixtures on $\mathrm{Ti}$, revealing an enhanced interaction of the IL with the underlying substrate. Similarly, we observed blue shifts of characteristic bands related to anions of the other ILs $\left[\mathrm{P}_{6,6,6,14}\right][\mathrm{DCA}]$, $\left[\mathrm{P}_{6,6,6,614}\right][\mathrm{BOB}],\left[\mathrm{P}_{6,6,6,14}\right][\mathrm{BMB}]$, and $\left[\mathrm{P}_{4,4,4,8}\right][\mathrm{BScB}]$ in the IL-oil mixtures on $\mathrm{Ti}$, in comparison with the corresponding neat bulk ILs (Fig. S2 in the ESM). The resulting strong interaction of ILs with the substrate facilitates the formation of tightly packed boundary layer which is further confirmed by AFM force curves and number density profiles. The formed boundary layer is expected to enable the reduction of friction coefficient on the surface of Ti.

\subsection{Nanoscale friction of IL-oil mixtures on the Ti substrate}

The nanoscale friction of the bare Ti substrate, the neat DEGDBE oil, and the ILs-oil mixtures on Ti surface is investigated using AFM. The relationship of the friction force $\left(F_{\mathrm{F}}\right)$ with the normal load $\left(F_{\mathrm{N}}\right)$ is obtained with $\mathrm{Si}_{3} \mathrm{~N}_{4}$ AFM tips, as shown in Fig. 5.

The friction coefficient, $\mu$, is defined as the gradient of the friction-load curve based on Amontons' law, $F_{\mathrm{F}}=\mu F_{\mathrm{N}}+F_{0}$. We observed in Fig. 5 that the line describing the linear friction-load relation does not extrapolate back to the origin but toward $F_{0}$ as $F_{\mathrm{N}}=0$, where $F_{0}$ is the friction at zero load attributed to the contribution of the adhesion force [54-56]. This 

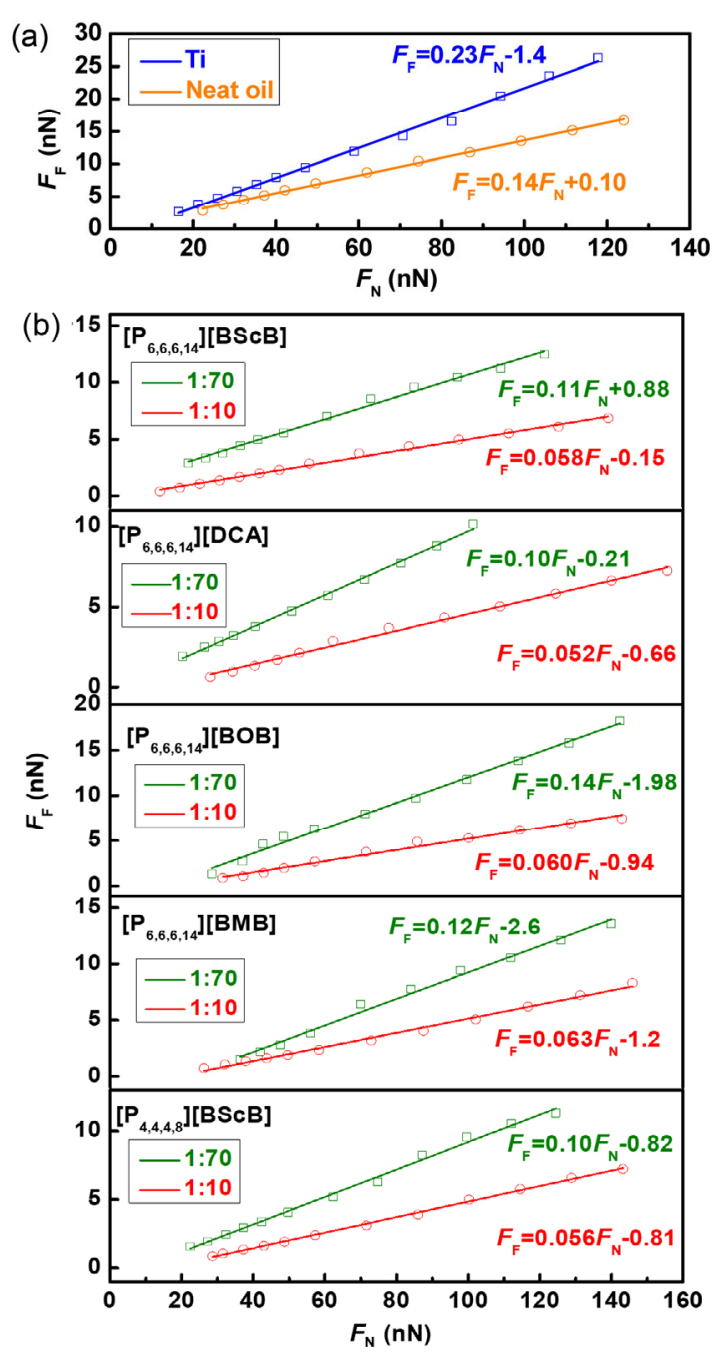

Fig. 5 Friction force measurements for (a) the bare Ti substrate and neat DEGDBE oil on Ti surface, (b) ILs-oil mixtures on Ti surface with varying molar ratio of the IL in the DEGDBE oil with silicon nitride AFM tip. The fitting slope in (a) and (b) is $\mu$. The raw friction data has been listed in Fig. S4 and Table S1 in the ESM.

adhesion is mainly from van der Waals, electrostatic, and capillary forces [57]. The capillary forces can be eliminated as the tip is immersed in the samples of IL-oil mixtures or neat oil coated on $\mathrm{Ti}$, and the non-meniscus adhesion is significantly dependent on the liquid media [58]. As exhibited in Fig. 5, as the liquid varies, the friction force extrapolated at zero load was found to be different, indicating different contributions of the adhesion to the nanoscale friction. The observed negative value of $F_{0}$, i.e., the negative intercept of the friction force versus normal load curves, means the attractive adhesion force at zero load [59]. However, the determination of adhesion forces does not depend on the lateral movement [60]. The pulloff adhesion force could be measured directly by separating the probe from the sample surface (Fig. S3 in the ESM).

In Fig. 5, as expected, the friction coefficient is the highest for the bare Ti substrate $(\mu=0.23)$, and the neat oil $(\mu=0.14)$ reduces its magnitude by approximately $50 \%$. For the ILs-oil mixtures, the friction coefficient decreases with increasing IL concentration (Fig. 5(b)). The friction coefficients for the bare Ti substrate, neat oil on Ti, and ILs-oil mixtures (molar ratios of 1:70, 1:10) on Ti are compared in Table 1.

Especially, the friction coefficient in the ILs-oil mixtures with a molar ratio of $1: 70(\mu \sim 0.10)$ is similar to or slightly lower than that of the neat DEGDBE oil. The higher IL concentration with a molar ratio of 1:10, enables a significant reduction in the friction coefficient ( $\mu \sim 0.052-0.063)$, most likely due to the tightly packed IL boundary layers on the Ti substrate (Fig. 8). In comparison, the boundary layer in the case of 1:70 remains incomplete during sliding because of the lower IL concentration, and the ions of the ILs could be displaced by the oil during the sliding motion, resulting in the similarity of the friction coefficients in 1:70 IL-oil mixture and neat oil.

\subsection{Layering structured ILs at the interfaces}

Typical approaching force-distance curves are obtained with AFM colloidal probes, to further examine the boundary layers of IL-oil mixtures at the Ti substrates, as shown in Fig. 6. Here we employed glass colloidal probes (dimension of $\sim 20 \mu \mathrm{m}$, the inset in Fig. 6(a)) to replace sharp AFM tips, because "the larger well-

Table 1 Nanofriction coefficients of the bare Ti substrate, neat DEGDBE oil on Ti surface, and ILs-oil mixtures (1:70, 1:10) on the Ti surface.

\begin{tabular}{cccc}
\hline $\begin{array}{c}\text { Molar ratio of } \\
\text { IL to oil }\end{array}$ & $1: 70$ & $1: 10$ & - \\
\hline Bare Ti & - & - & $0.23 \pm 0.001$ \\
Neat oil & - & - & $0.14 \pm 0.005$ \\
{$\left[\mathrm{P}_{6,6,6,14}\right][\mathrm{BScB}]$} & $0.11 \pm 0.001$ & $0.058 \pm 0.004$ & - \\
{$\left[\mathrm{P}_{6,6,6,14}\right][\mathrm{DCA}]$} & $0.10 \pm 0.001$ & $0.052 \pm 0.001$ & - \\
{$\left[\mathrm{P}_{6,6,6,14}\right][\mathrm{BOB}]$} & $0.14 \pm 0.001$ & $0.060 \pm 0.001$ & - \\
{$\left[\mathrm{P}_{6,6,6,14}\right][\mathrm{BMB}]$} & $0.12 \pm 0.003$ & $0.063 \pm 0.002$ & - \\
{$\left[\mathrm{P}_{4,4,4,8}\right][\mathrm{BScB}]$} & $0.10 \pm 0.003$ & $0.056 \pm 0.001$ & - \\
\hline
\end{tabular}



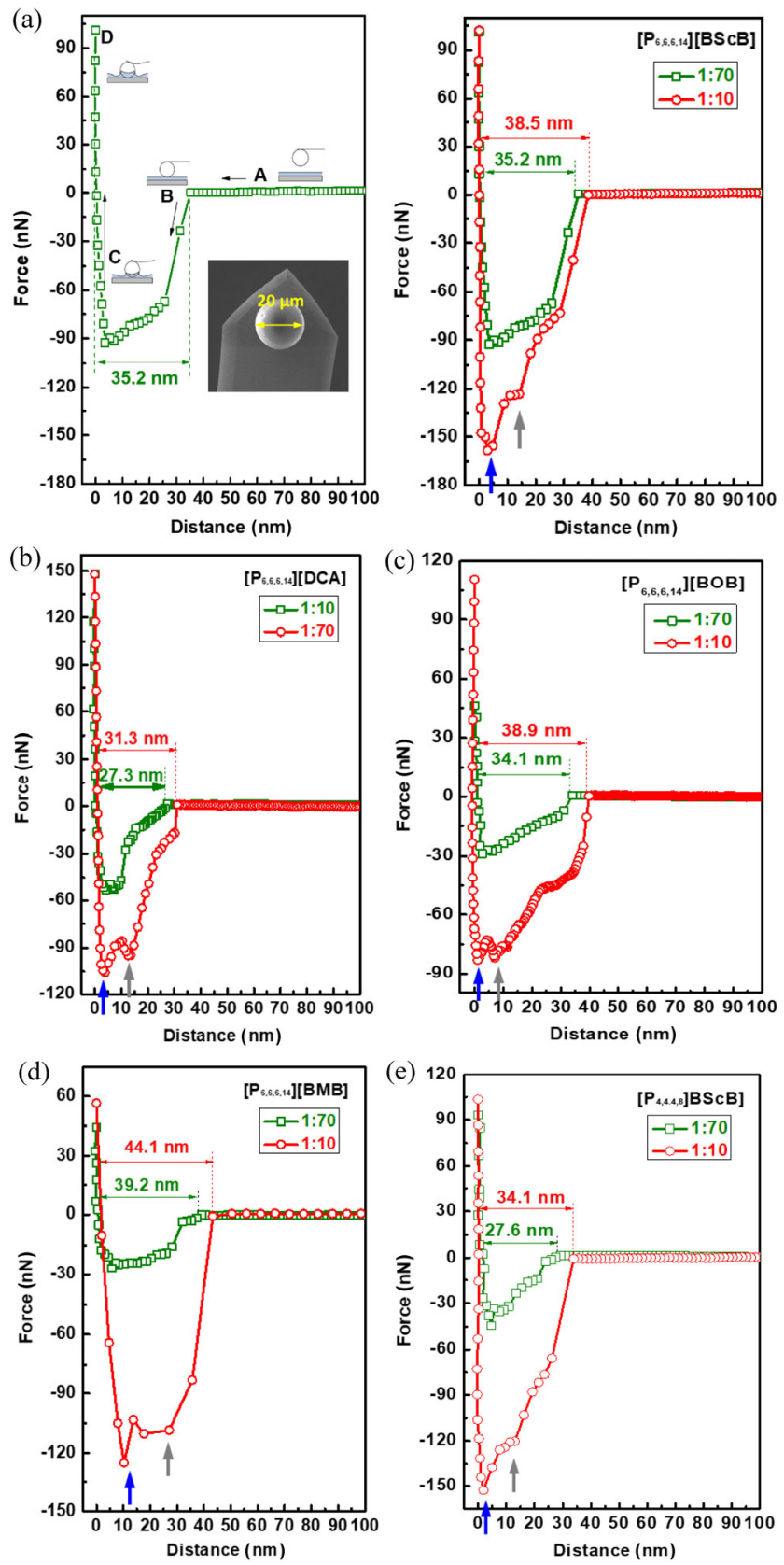

Fig. 6 Representative approaching force-distance curves for ILs-oil mixtures (1:70 and 1:10) coated Ti surfaces with AFM colloidal probes. (a) $\left[\mathrm{P}_{6,6,6,14}\right][\mathrm{BScB}]$, and the left panel is an AFM glass colloidal probe approaching the liquid film of $\left[\mathrm{P}_{6,6,6,14}\right][\mathrm{BScB}]$-oil mixture $(1: 70)$ on the Ti surface (A-D), the probe being retracted after contact (shown in Fig. S3 in the ESM). The inset is a borosilicate glass microsphere attached to a tipless $\mathrm{Si}_{3} \mathrm{~N}_{4}$ cantilever with a dimension of $20 \mu \mathrm{m}$; (b) $\left[\mathrm{P}_{6,6,6,14}\right][\mathrm{DCA}]$; (c) $\left[\mathrm{P}_{6,6,6,14}\right][\mathrm{BOB}]$; (d) $\left[\mathrm{P}_{6,6,6,14}\right][\mathrm{BMB}]$; and (e) $\left[\mathrm{P}_{4,4,4,8}\right][\mathrm{BScB}]$. The blue and grey arrows correspond to two interfacial layers.

defined interaction area afforded by the colloidal probe increases measurement sensitivity and reduces the possibility that an isolated surface asperity produces unrepresentative force data" [38].

Figure 6(a) (left) exhibits an AFM glass colloidal probe approaching toward the liquid film of $\left[\mathrm{P}_{6,6,6,14}\right][\mathrm{BScB}]-$ oil mixture (1:70) at the Ti surface $(\mathrm{A}-\mathrm{C})$. Then a force was observed to increase in a steep linear way at D, indicating that the probe has been in contact with the Ti surface. The film thickness of the $\left[\mathrm{P}_{6,6,6,14}\right][\mathrm{BScB}]-$ oil mixture (1:70) on Ti can be inferred as $35.2 \mathrm{~nm}$, from the difference between the jump-in position and the zero-force point on the contact line (green horizontal double head arrow). Figure 6 also shows typical approaching force curves for the other IL-oil films on Ti substrates, from which, the film thicknesses could be obtained as 38.5, 27.3, 31.3, 34.1, 38.9, 39.2, 44.1, 27.6, $34.1 \mathrm{~nm}$, respectively for $\left[\mathrm{P}_{6,6,6,14}\right][\mathrm{BScB}]$-oil $(1: 10)$,

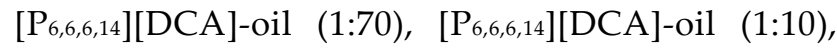
$\left[\mathrm{P}_{6,6,6,14}\right][\mathrm{BOB}]$-oil (1:70), [P,6,6,64][BOB]-oil (1:10), [P, $6,6,6,14][\mathrm{BMB}]$-oil (1:70), [P6,6,6,14][BMB]-oil (1:10), $\left[\mathrm{P}_{4,4,4,8}\right][\mathrm{BScB}]-$ oil $(1: 70)$, and $\left[\mathrm{P}_{4,4,4,8}\right][\mathrm{BScB}]$-oil (1:10) on Ti. Apparently, the film thickness of IL-oil mixtures is larger in 1:10 than that in 1:70. In addition, the thickness of the neat oil on $\mathrm{Ti}$ is $18.5 \mathrm{~nm}$, as observed in Fig. S3(b) in the ESM.

In Fig. 6, the major features for all ILs-oil mixtures with a molar ratio of 1:10, consist of two steps at discrete separations, corresponding to the two interfacial layers, in which, the force required to penetrate a layer is referred to as the push-through force. As is known from the previous work, the magnitude of the pushthrough force indicates the degree of order in a layered structure, where a higher force reflects a stronger order [38]. Thus, the observed stronger push-through force closer to the surface of the substrate (blue arrow), is indicative of a more ordered layer. While the probe encounters a less pronounced layer at a greater distance to the underlying substrate (grey arrow), and it pushes against this layer with a weaker pushthrough force.

However, no step-like force behavior was observed in the IL-oil mixtures with 1:70 molar ratio during approach, where the probe first contacts the IL-oil mixture surface and the attractive force gradually increases on continued approach. As the tip eventually encounters the hard Ti substrate, a drastic collapse is observed in the force at zero tip-sample distance. 
The disappeared ordered layer in the case of 1:70, is probably ascribed to the lower IL concentration, resulting in an incomplete boundary layer on the $\mathrm{Ti}$ surface.

Noting that the values of the forces in the approaching force curves are observed to be attractive in Fig. 6. According to the explanations in Atkin's group, the attractive force is probably due to 1) the repulsions being completely masked by the attractive dispersion forces[61]; and 2) the surface-induced IL nanostructures [38]. As for the latter explanation, Atkin's group had suggested that "the bulk sponge structure presenting in many ILs is transformed to a more layered structure by the underlying surface" [62]. This surface-induced nanostructural transformation in ILs is analogous to surface-induced phase transition from sponge to lamellar in aqueous surfactant [63, 64], where an attractive force was caused by the capillary condensation of the lamellar phase. A similar effect of aqueous surfactant was contended to be in operation for the attractive forces observed in the approaching force curves in ILs [38].

The number density profile [65-67] of the $\left[\mathrm{P}_{6,6,6,14}\right][\mathrm{BScB}]$-oil mixture $(1: 10)$ along the direction perpendicular to the substrate was calculated by molecular dynamics (MD) simulation to reveal the spatial distribution of the cation, anion, and molecules of the DEGDBE oil in a slit pore (pore width of $10.7 \mathrm{~nm}$ ) composed of graphene and rutile. Since the Ti surface is usually covered by a native dense titanium dioxide $\left(\mathrm{TiO}_{2}\right)$ layer [42], we employed rutile- $\mathrm{TiO}_{2}$ as the model substrate, and the AFM tip is modeled by a bilayer graphene. The spatial distribution of ions and oil would provide a better understanding of the observed layering structure of the IL-oil mixture with a molar ratio of 1:10 at the Ti substrate.

The pronounced layered spatial distributions for both $\left[\mathrm{P}_{6,6,6,14}\right]^{+}$and $[\mathrm{BSCB}]^{-}$are found in Fig. 7 . Tighter packing density of ions was observed near the surface of slit pore, referring as the dense layer $\left(t_{\mathrm{LD}}\right)$, with less prominent ion density peaks at the position further away from the surface (loose layer, $t_{\mathrm{LL}}$ ). The formed ordered IL-rich layers $\left(t_{\mathrm{LD}}+t_{\mathrm{LL}}\right)$, would prevent the direct substrate-to-substrate contact, facilitating the reduction of the nanofriction [68].

In the center of the slit pore, which is at a greater distance to the surface of the slit pore, no obvious ion

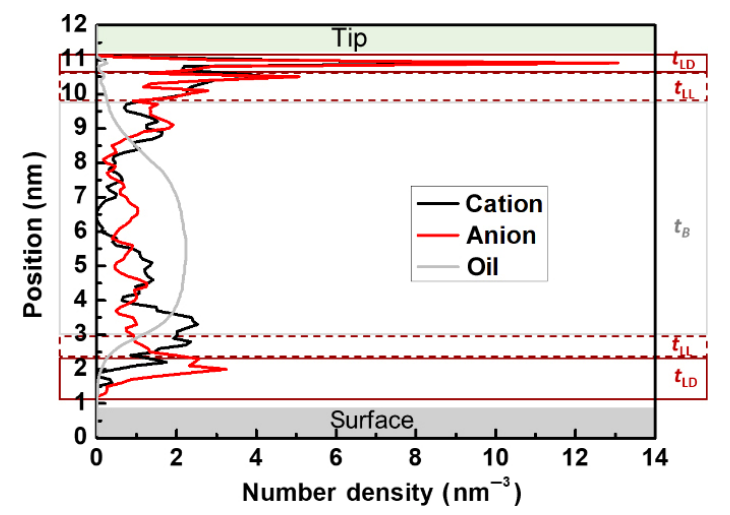

Fig. 7 Number density profiles of cations, anions, as well as the oil in $\left[\mathrm{P}_{6,6,6,14}\right][\mathrm{BScB}]$-oil mixtures (1:10 molar ratio) confined between the bilayer graphene tip and rutile (110) surface at a slit pore width of $10.7 \mathrm{~nm}$.

density peak was found, while a broad density peak of the oil appears in this regime. Thus, the existing fewer ions, together with the dispersed oil, formed a third oil-rich regime, similar to the bulk oil phase ( $t_{B}$, Fig. 8). The observed three distinct layers agreed well with a recent simulation findings, in which, the slits confined IL exhibits an apparent triple layered spatial distribution [69].

The number density profile suggests that the ions of ILs prefer to accumulate at the surface to form a layered structure, as illustrated in Fig. 8 (right panel). The thickness of the IL-rich layered structure $\left(t_{\mathrm{L}}\right)$ consists of dense $\left(t_{\mathrm{LD}}\right)$ and loose $\left(t_{\mathrm{LL}}\right)$ layers. The dense layer is the ordered IL layers adjacent to the underlying surface, while the latter one is the upper IL with decayed ordering at a greater distance from the surface. The IL-rich layered structure confirms the observation of a more ordered layer closer to the surface in forcedistance profiles as shown in Fig. 6.

The magnitude of the nanofriction coefficient could be determined largely by the layered structure $\left(t_{\mathrm{L}}\right)$ formed at interfaces. We have previously found a monotonical increase of $\mu$ with decreasing $t_{\mathrm{L}}$ [41]. Because the layering assembled IL closer to the underlying surface is more ordered, resulting in a stronger interaction for the same value of contact area and thus a higher friction. As for the lower IL concentration (1:70), the formed layering structured IL is incomplete (left panel in Fig. 8), so the displacement of ions by the oil would occur, resulting in a higher friction coefficient.

It is worth noting that the upper IL layers $\left(t_{\mathrm{LL}}\right)$ is 

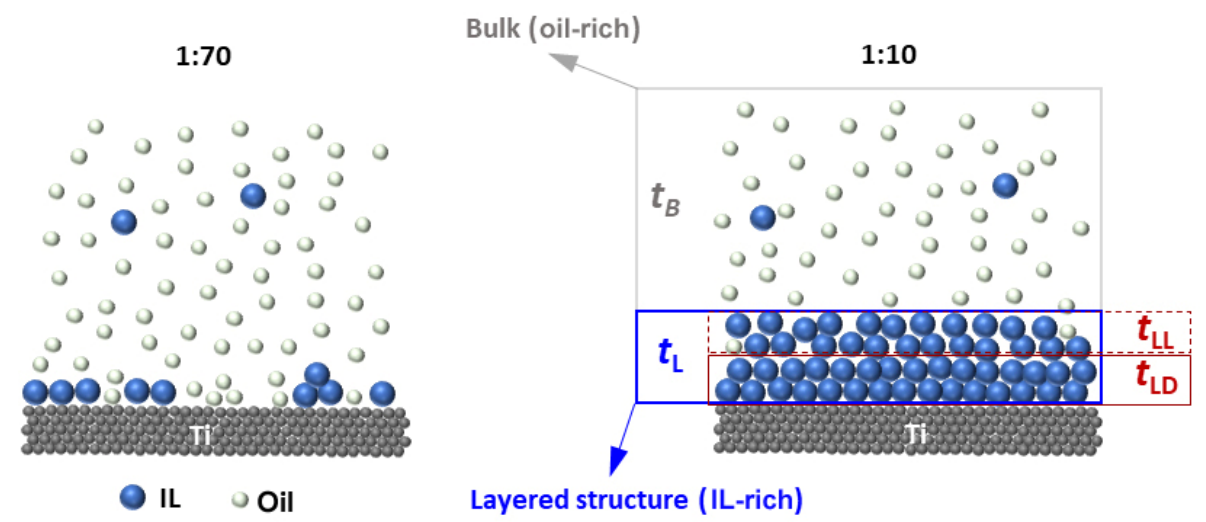

Fig. 8 Schematic illustration of the IL-oil mixtures (molar ratio of 1:70, 1:10) distributed at Ti interfaces. The thickness of the ordered IL layers $\left(t_{\mathrm{L}}\right)$ is composed of dense and loose layers. $t_{\mathrm{LD}}$ : the thickness of the near surface denser layer; $t_{\mathrm{LL}}$ : the thickness of the upper slightly looser layer.

less stable, and the existing oil at a greater distance to the substrate prevents the escape of the ions from the layer $t_{\mathrm{LL}}$. A further increase of the ions of ILs, results in a smaller fraction of the oil which cannot ensure the stability of $t_{\mathrm{LL}}$ layer, and would not necessarily bring a smaller friction coefficient. Our previous findings revealed that phosphonium orthoborate ILs and DEGDBE oil mixtures with a molar ratio of $\sim 1: 1$ resulted in a negative load-dependent friction behavior, not following the Amontons' law [24]. The observed negative friction-load dependence where the friction decreases with the increasing normal load, was attributed to the structural reorientation of the ILs. In addition, the magnitude of the measured friction in the case of 1:1 was much higher than that in the case of dilute solutions with molar ratios of 1:70 and 1:10.

\section{Conclusions}

The interactions and nanofriction behavior of nonhalogenated phosphonium-based ILs as additives to the oil diethylene glycol dibutyl ether with molar ratios of 1:10 and 1:70 were investigated on titanium surface using AFM. The $\mu$ for the ILs-oil mixtures with a molar ratio of 1:70 is $\sim 0.1$, which is similar or slightly lower as compared to the neat DEGDBE oil. On the contrary, the higher IL concentration with a molar ratio of 1:10 significantly reduced the $\mu(\sim 0.05)$. It is found that the higher IL concentration leads to tightly packed boundary layers on the Ti substrate, while the lower ILs concentration results in incomplete boundary layers and the ions of ILs are displaced by the molecules of oil during sliding.

The approaching force-distance curves and number density profiles for the higher ILs concentration revealed a tighter packing density of ions near the surface (dense layer, $t_{\mathrm{LD}}$ ). The less prominent ion density peak further away from the surface confirmed a loose layer, $t_{\mathrm{LL}}$. The formed ordered IL-rich layers $\left(t_{\mathrm{LD}}+t_{\mathrm{LL}}\right)$, prevented the direct substrate-to-substrate contact, facilitating the reduction of the nanofriction. On the other hand, the ordered IL layer disappeared in the case of a lower IL concentration, which results in an incomplete boundary layer and a less effective friction reduction on Ti substrate. It is observed that the upper loose IL layer is less stable, through which, the escape of the ions might occur, and the existing oil on the top at a greater distance to the substrate could block this escape. Thus, a further increase of the IL would not necessarily bring a smaller friction coefficient, because it results in a smaller fraction of the oil which cannot ensure the block of the ion escape.

\section{Acknowledgements}

We are grateful to the support from Natural Science Foundation of Jiangsu Province (Grant No. BK20191289), the National Natural Science Foundation of China (Grant Nos. 21838004, 21606131, and 21676137), and the financial support from Instrument \& Equipment Open Funding of Nanjing University of Science and Technology. The Swedish Foundation for Strategic Research (Grant No. EM16-0013) is also gratefully acknowledged for the financial support. 
Electronic Supplementary Material: Supplementary material is available in the online version of this article at https://doi.org/10.1007/s40544-021-0486-4.

Open Access This article is licensed under a Creative Commons Attribution 4.0 International License, which permits use, sharing, adaptation, distribution and reproduction in any medium or format, as long as you give appropriate credit to the original author(s) and the source, provide a link to the Creative Commons licence, and indicate if changes were made.

The images or other third party material in this article are included in the article's Creative Commons licence, unless indicated otherwise in a credit line to the material. If material is not included in the article's Creative Commons licence and your intended use is not permitted by statutory regulation or exceeds the permitted use, you will need to obtain permission directly from the copyright holder.

To view a copy of this licence, visit http://creativecommons.org/licenses/by/4.0/.

\section{References}

[1] Holmberg K, Erdemir A. The impact of tribology on energy use and $\mathrm{CO}_{2}$ emission globally and in combustion engine and electric cars. Tribol Int 135: 389-396 (2019)

[2] Zhou F, Liang Y, Liu W. Ionic liquid lubricants: Designed chemistry for engineering applications. Chem Soc Rev 38: 2590-2599 (2009)

[3] Jones Jr W R, Jansen M J. Space tribology. In NASA Technical Report NASA-TM-209924, Ohio, USA, 2000: 1-11.

[4] Tripathi M, Awaja F, Paolicelli G, Bartali R, Iacob E, Valeri S, Ryu S, Signetti S, Speranza G, Pugno N M. Tribological characteristics of few-layer graphene over $\mathrm{Ni}$ grain and interface boundaries. Nanoscale 8: 6646-6658 (2016)

[5] Hayes R, Warr G G, Atkin R. Structure and nanostructure in ionic liquids. Chem Rev 115: 6357-6426 (2015)

[6] Wang Y, Wang C, Zhang Y, Huo F, He H, Zhang S. Molecular insights into the regulatable interfacial property and flow behavior of confined ionic liquids in graphene nanochannels. Small 15: 1804508 (2019)

[7] Zhang S, Zhang J, Zhang Y, Deng Y. Nanoconfined ionic liquids. Chem Rev 117: 6755-6833 (2017)

[8] Zhou Y, Qu J. Ionic liquids as lubricant additives: a review. ACS Appl Mater Interfaces 9: 3209-3222 (2017)

[9] Hjalmarsson N, Atkin R, Rutland M W. Is the boundary layer of an ionic liquid equally lubricating at higher temperature? Phys Chem Chem Phys 18: 9232-9239 (2016)

[10] Hayes R, Imberti S, Warr G G, Atkin R. Amphiphilicity determines nanostructure in protic ionic liquids. Phys Chem Chem Phys 13: 3237-3247 (2011)

[11] Ray A. Solvophobic interactions and micelle formation in structure forming nonaqueous solvents. Nature 231: 313-315 (1971)

[12] Greaves T L, Weerawardena A, Krodkiewska I, Drummond C J. Protic ionic liquids: Physicochemical properties and behavior as amphiphile self-assembly solvents. J Phys Chem B 112: 896-905 (2008)

[13] Triolo A, Russina O, Bleif H-J, Di Cola E. Nanoscale segregation in room temperature ionic liquids. $J$ Phys Chem B 111: 4641-4644 (2007)

[14] Fan M, Yang D, Wang X, Liu W, Fu H. Doss- based qails: As both neat lubricants and lubricant additives with excellent tribological properties and good detergency. Ind Eng Chem Res 53: 17952-17960 (2014)

[15] Li H, Somers A E, Howlett P C, Rutland M W, Forsyth M, Atkin R. Addition of low concentrations of an ionic liquid to a base oil reduces friction over multiple length scales: A combined nano-and macrotribology investigation. Phys Chem Chem Phys 18: 6541-6547 (2016)

[16] Taher M, Shah F U, Filippov A, De Baets P, Glavatskih S, Antzutkin O N. Halogen-free pyrrolidinium bis(mandelato) borate ionic liquids: Some physicochemical properties and lubrication performance as additives to polyethylene glycol. RSC Adv 4: 30617-30623 (2014)

[17] Rohlmann P, Munavirov B, Furó I, Antzutkin O, Rutland M W, Glavatskih S. Non-halogenated ionic liquid dramatically enhances tribological performance of biodegradable oils. Front Chem 7: 98 (2019)

[18] Cai M, Yu Q, Zhou F, Liu W. Physicochemistry aspects on frictional interfaces. Friction 5(4): 361-382 (2017)

[19] Zhang J, Meng Y. Boundary lubrication by adsorption film. Friction 3(2): 115-147 (2015)

[20] Meng Y, Xu J, Jin Z, Prakash B, Hu Y. A review of recent advances in tribology. Friction 8(2): 221-300 (2020)

[21] Qu J, Bansal D G, Yu B, Howe J Y, Luo H, Dai S, Li H, Blau P J, Bunting B G, Mordukhovich G, Smolenski D J. Antiwear performance and mechanism of an oil-miscible ionic liquid as a lubricant additive. ACS Appl Mater Interfaces 4: 997-1002 (2012)

[22] Pejaković V, Tomastik C, Dörr N, Kalin M. Influence of concentration and anion alkyl chain length on tribological properties of imidazolium sulfate ionic liquids as additives to glycerol in steel-steel contact lubrication. Tribol Int $\mathbf{9 7}$ : 234-243 (2016) 
[23] Jiang D, Hu L, Feng D. Tribological properties of crowntype phosphate ionic liquids as lubricating additives in rapeseed oils. Lubr Sci 25: 195-207 (2013)

[24] An R, Zhou G, Zhu Y, Zhu W, Huang L, Shah F U. Friction of ionic liquid-glycol ether mixtures at titanium interfaces: negative load dependence. Adv Mater Interfaces 5: 1800263 (2018)

[25] Nicholls M A, Do T, Norton P R, Kasrai M, Bancroft G M. Review of the lubrication of metallic surfaces by zinc dialkyldithiophosphates. Tribol Int 38: 15-39 (2005)

[26] Suzuki A, Shinka Y, Masuko M. Tribological characteristics of imidazolium-based room temperature ionic liquids under high vacuum. Tribol Lett 27: 307-313 (2007)

[27] Kondo Y, Yagi S, Koyama T, Tsuboi R, Sasaki S. Lubricity and corrosiveness of ionic liquids for steel-on-steel sliding contacts. Proc Inst Mech Eng Part J: J Eng Tribol 226: 991-1006 (2012)

[28] Ye C, Liu W, Chen Y, Yu L. Room-temperature ionic liquids: A novel versatile lubricant. Chem Commun 21: 2244-2245 (2001)

[29] Minami I. Ionic liquids in tribology. Molecules 14: 2286-2305 (2009)

[30] Swatloski R P, Holbrey J D, Rogers R D. Ionic liquids are not always green: Hydrolysis of 1-butyl-3-methylimidazolium hexafluorophosphate. Green Chem 5: 361-363 (2003)

[31] Wasserscheid P, Van Hal R, Bosmann A. 1-n-butyl-3methylimidazolium (bmim) octylsulfate-An even 'greener' ionic liquid. Green Chem 4: 400-404 (2002)

[32] Pattee H E, Monroe R E. Adhesion in the space environment. In NASA Technical Report NASA-TM-X59395, Alabama, USA, 1966: 1-109.

[33] Zhang X Y, Hua Y X, Xu C Y, Zhang Q B, Cong X B, Xu $N$. Direct electrochemical reduction of titanium dioxide in Lewis basic $\mathrm{AlCl}_{3}$-1-butyl-3-methylimidizolium ionic liquid. Electrochim Acta 56: 8530-8533 (2011)

[34] Flower H M. A moving oxygen story. Nature 407: 305-306 (2000)

[35] Li H, Somers A E, Rutland M W, Howlett P C, Atkin R. Combined nano-and macrotribology studies of titania lubrication using the oil-ionic liquid mixtures. ACS Sustain Chem Eng 4: 5005-5012 (2016)

[36] Liu X, Chu P K, Ding C. Surface modification of titanium, titanium alloys, and related materials for biomedical applications. Mat Sci Eng R: 47: 49-121 (2004)

[37] Kaur S, Ghadirinejad K, H. Oskouei R. An overview on the tribological performance of titanium alloys with surface modifications for biomedical applications. Lubricants 7 : 65-79 (2019)
[38] Li H, Endres F, Atkin R. Effect of alkyl chain length and anion species on the interfacial nanostructure of ionic liquids at the $\mathrm{Au}$ (111)-ionic liquid interface as a function of potential. Phys Chem Chem Phys 15: 14624-14633 (2013)

[39] Shah F U, Glavatskih S, Macfarlane D R, Somers A, Forsyth M, Antzutkin O N. Novel halogen-free chelated orthoborate-phosphonium ionic liquids: Synthesis and tribophysical properties. Phys Chem Chem Phys 13: 12865 12873 (2011)

[40] Liu W, Bonin K, Guthold M. Easy and direct method for calibrating atomic force microscopy lateral force measurements. Rev Sci Instrum 78: 063707 (2007)

[41] An R, Qiu X, Shah F U, Riehemann K, Fuchs H. Controlling the nanoscale friction by layered ionic liquid films. Phys Chem Chem Phys 22:14941-14952 (2020)

[42] Buettner K M, Valentine A M. Bioinorganic chemistry of titanium. Chem Rev 112: 1863-1881 (2012)

[43] Wang D H, Hu Y, Zhao J J, Zeng L L, Tao X M, Chen W. Holey reduced graphene oxide nanosheets for high performance room temperature gas sensing. $J$ Mater Chem $A$ 2: $17415-17420(2014)$

[44] Nasybulin E, Xu W, Engelhard M H, Nie Z, Burton S D, Cosimbescu L, Gross M E, Zhang J-G. Effects of electrolyte salts on the performance of $\mathrm{Li}-\mathrm{O}_{2}$ batteries. J Phys Chem C 117: 2635-2645 (2013)

[45] Ozturk B, De-Luna-Bugallo A, Panaitescu E, Chiaramonti A N, Liu F, Vargas A, Jiang X, Kharche N, Yavuzcetin O, Alnaji M, Ford M J, Lok J, Zhao Y, King N, Dhar N K, Dubey M, Nayak S K, Sridhar S, Kar S. Atomically thin layers of B-N-C-O with tunable composition. Sci Adv 1: e1500094 (2015)

[46] Hu J, Diao H, Luo W, Song Y-F. Dawson-type polyoxomolybdate anions $\left(\mathrm{P}_{2} \mathrm{Mo}_{18} \mathrm{O}_{62}{ }^{6-}\right)$ captured by ionic liquid on graphene oxide as high-capacity anode material for lithium-ion batteries. Chem-Eur J 23: 8729-8735 (2017)

[47] Peng B, Xu Y, Liu K, Wang X, Mulder F M. High-performance and low-cost sodium-ion anode based on a facile black phosphorus-carbon nanocomposite. ChemElectroChem 4: 2140-2144 (2017)

[48] Armelao L, Barreca D, Bottaro G, Canevali C, Morazzoni F, Scotti R, Tondello E. Boron and phosphorus quantification in sol-gel BPSG glasses by XPS. Surf Sci Spectra 10: 40-46 (2003)

[49] Mishra A, Sahoo R K, Singh S K, Mishra B K. Synthesis of low carbon boron carbide powder using a minimal time processing route: thermal plasma. J Asian Ceram Soc 3: 373-376 (2015)

[50] Shah F U, Gnezdilov O I, Filippov A. Ion dynamics in 
halogen-free phosphonium bis(salicylato)borate ionic liquid electrolytes for lithium-ion batteries. Phys Chem Chem Phys 19: 16721-16730 (2017)

[51] Logacheva N M, Baulin V E, Tsivadze A Y, Pyatova E N, Ivanova I S, Velikodny Y A, Chernyshev V V. Ni(II), Co(II), $\mathrm{Cu}(\mathrm{II}), \mathrm{Zn}$ (II) and $\mathrm{Na}$ (I) complexes of a hybrid ligand 4'-(4'"'benzo-15-crown-5)-methyloxy-2,2':6',2"-terpyridine. Dalton Trans: 2482-2489 (2009)

[52] Gusain R, Singh R, Sivakumar K L N, Khatri O P. Halogen-free imidazolium/ammonium-bis(salicylato)borate ionic liquids as high performance lubricant additives. RSC Adv 4: 1293-1301 (2014)

[53] Bakshi P S, Gusain R, Khatri O P. Microtribological properties of a spin-coated thin film of 1-butyl-3(propyltrimethoxysilane)imidazolium bis(mandelato)borate ionic liquid. RSC Adv 6: 78296-78302 (2016)

[54] Quignon B, Pilkington G A, Thormann E, Claesson P M, Ashfold M N R, Mattia D, Leese H, Davis S A, Briscoe W H. Sustained frictional instabilities on nanodomed surfaces: Stick-slip amplitude coefficient. ACS Nano 7: 10850-10862 (2013)

[55] Smith A M, Lovelock K R, Gosvami N N, Welton T, Perkin S. Quantized friction across ionic liquid thin films. Phys Chem Chem Phys 15: 15317-15320 (2013)

[56] Leng Y, Jiang S. Dynamic simulations of adhesion and friction in chemical force microscopy. J Am Chem Soc 124: 11764-11770 (2002)

[57] Pethica J B, Oliver W C. Tip surface interactions in stm and afm. Phys Scr 1987: 61-66 (1987)

[58] Robinson B J, Kay N D, Kolosov O V. Nanoscale interfacial interactions of graphene with polar and nonpolar liquids. Langmuir 29: 7735-7742 (2013)

[59] Tambe N S, Bhushan B. Identifying materials with low friction and adhesion for nanotechnology applications. Appl Phys Lett 86: 061906 (2005)

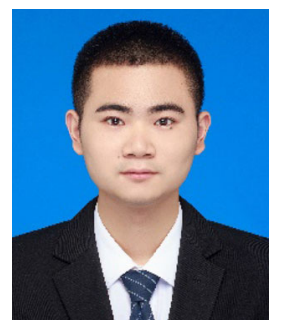

Xiuhua QIU. He received his bachelor degree in materials science in 2017 from Henan Polytechnic University, China. He joined Herbert Gleiter Institute of Nanoscience,
[60] Bhushan B, LaTorre C, Wei G. In Springer handbook of nanotechnology. Bhushan, B, Ed. Berlin: Springer, 2007: 1276-1280.

[61] Smith J A, Werzer O, Webber G B, Warr G G, Atkin R. Surprising particle stability and rapid sedimentation rates in an ionic liquid. J Phys Chem Lett 1: 64-68 (2010)

[62] Hayes R, Warr G G, Atkin R. At the interface: solvation and designing ionic liquids. Phys Chem Chem Phys 12: 1709-1723 (2010)

[63] Hamilton W A, Porcar L, Butler P D, Warr G G. Local membrane ordering of sponge phases at a solid-solution interface. J Chem Phys 116: 8533-8546 (2002)

[64] Antelmi D A, Kékicheff P, Richetti P. The confinementinduced sponge to lamellar phase transition. Langmuir 15: 7774-7788 (1999)

[65] Dragoni D, Manini N, Ballone P. Interfacial layering of a room-temperature ionic liquid thin film on mica: a computational investigation. Chemphyschem 13: 1772-1780 (2012)

[66] Dyatkin B, Osti N, Zhang Y, Wang H-W, Mamontov E, Heller W T, Zhang P, Rother G, Cummings P, Wesolowski D J, Gogotsi Y. Ionic liquid structure, dynamics, and electrosorption in carbon electrodes with bimodal pores and heterogeneous surfaces. Carbon 129: 104-118 (2018)

[67] Alibalazadeh M, Foroutan M. Specific distributions of anions and cations of an ionic liquid through confinement between graphene sheets. J Mol Model 21: 168 (2015)

[68] Comtet J, Niguès A, Kaiser V, Coasne B, Bocquet L, Siria A. Nanoscale capillary freezing of ionic liquids confined between metallic interfaces and the role of electronic screening. Nat Mater 16: 634-639 (2017)

[69] Dai Z, You Y, Zhu Y, Wang S, Zhu W, Lu X. Atomistic insights into the layered microstructure and time-dependent stability of $[\mathrm{BMIM}]\left[\mathrm{PF}_{6}\right]$ confined within the meso-slit of carbon. J Phys Chem B 123: 6857-6869 (2019)

Department of Materials Science and Engineering, at Nanjing University of Science and Technology, as a master student since 2017. He is now focusing on the studies about the nanotribological behavior of ionic liquids. 


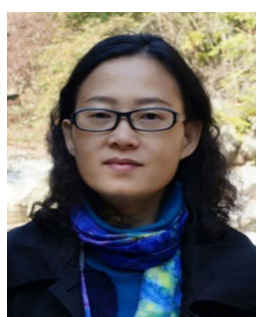

Linghong LU. She received her master degree in engineering from Harbin Engineering University, China, in 2000, and Ph.D. degree in Science from Zhejiang University, China, in 2005. She joined the College of

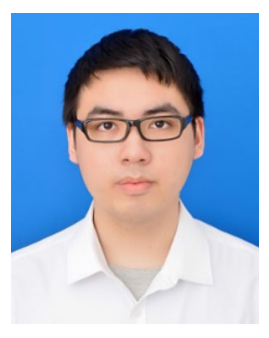

Zhenyu QU. He is a senior undergraduate student in Department of Materials Science and Engineering at Nanjing University of Science

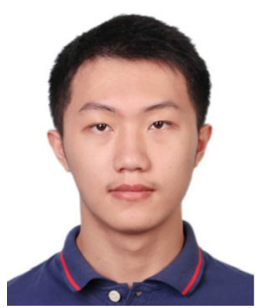

Jiongtao LIAO. He is a senior undergraduate student in Department of Materials Science and Engineering

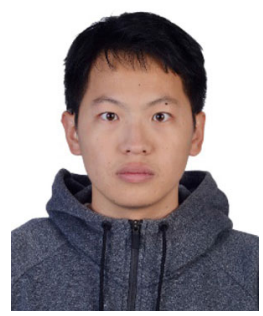

Qi FAN. He is a senior undergraduate student in Department of Materials Science and Engineering at Nanjing University of Science and

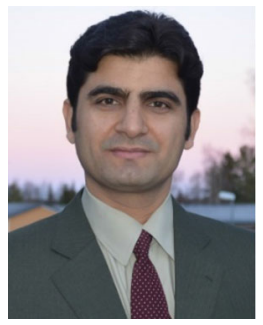

Faiz Ullah SHAH. He received his Ph.D. degree in Chemistry of Interfaces, Luleå University of Technology, Sweden, in 2011. He joined Chemistry of Interfaces, Luleå
Chemical Engineering of Nanjing Tech University from 2005. Her current position is a professor. Her research areas cover molecular simulation, structural property of confined fluid, adsorption, separation, and electrode materials.

and Technology, China. His research interests include nanotribological properties of different functional materials and heterogeneously structured surfaces.

at Nanjing University of Science and Technology, China. His research interests include ionic liquids behavior at solid interfaces and nano-tribology.

Technology, China. His research interests include the quantitative analysis of single molecular forces of charged surfaces with ionic liquids and lithium-sulfur batteries.

University of Technology, from 2011. His current position is an associate professor. His research areas cover the synthesis of ionic liquids and the applications, e.g., batteries, lubricants, and gas separation. 


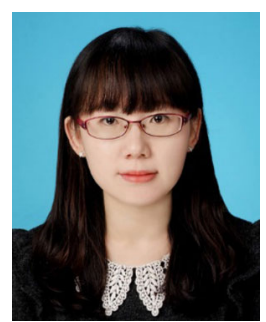

Wenling ZHANG. She received her Ph.D. degree from Inha University, Korea in 2015 and joined University of Alberta, Canada as a postdoc (2018-2019). She is currently a pro-

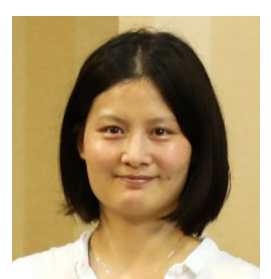

Rong AN. She received her Ph.D. degree in chemical engineering from Nanjing Tech University, China, in 2013. Then she worked as a postdoc researcher in Chemical and Biomolecular Engineering at North Carolina State University from 2013 to 2015. She joined Herbert fessor at the School of Mechanical Engineering, Nanjing University of Science and Technology. Her research interests focus on soft matters (electro/ magneto-rheological phenomena) and nanotribology (adhesion, friction, and lubrication).
Gleiter Institute of Nanoscience, Department of Materials Science and Engineering, at Nanjing University of Science and Technology from 2015. Her current position is an associate professor. Her research interests include the nanotribology of ionic liquids at solid interfaces, liquid-solid interfacial phenomena, and gas separation, etc. 